\title{
PENGARUH PDRB SEKTOR PERTANIAN UPAH MINIMUM PROVINSI TERHADAP PENYERAPAN TENAGA KERJA SEKTOR PERTANIAN DI PROVINSI JAMBI
}

\author{
Hasan Basri ${ }^{1}$ \\ Dosen Tetap Universitas Muhammadiyah Jambi ${ }^{1}$ \\ hasan.stiemjbi@gmail.com \\ Adi Putra ${ }^{2}$ \\ Dosen Tetap Universitas Muhammadiyah Jambi ${ }^{2}$ \\ putramm@,yahoo.co.id
}

\begin{abstract}
ABSTRAK
Tujuan yang ingin dicapai pada penelitian ini yaitu untuk mengetahui bagaimana perkembangan serta pengaruh PDRB sektor pertanian, Upah Minimum Provinsi terhadap penyerapan tenaga kerja sektor pertanian di Provinsi Jambi untuk menganalisis tersebut jenis data penelitian yang dipergunakan pada penelitian ini berupa data sekunder yang bersumber dari publikasi ilmiah dari lembaga pemerintah berupa data jumlah Tenaga Kerja Sektor Pertanian, PDRB sektor pertanian dan UMP Provinsi Jambi. Metode analisis data pada penelitian ini adalah menggunakan analisis deskriptif dan analisi kuantitatif, dimana analisis deskriptif dilakukan dengan tujuan untuk mengambarkan secara sistematis variabel yang di analisis sedangkan analisis kuantitatif digunakan untuk mengetahui faktor-faktor apa saja yang mempengaruhi penyerapan tenaga kerja sektor pertanian di Provinsi Jambi selama periode penelitian tersebut. Hasil penelitian didapatkan dapat dikemukakan dimana penyerapan tenaga kerja sektor pertanian di Provinsi Jambi bernilai negatif pada saat kondisi PDRB sektor pertanian dan UMP tidak mengalami peningkatan, tetapi jika nilai PDRB sektor pertanian dan UMP meningkat maka penyerapan tenaga kerja di sektor pertanian juga mengalami peningkatan. Pentingnya kontribusi PDRB sektor Pertanian dan Upah Minimum Provinsi terhadap peningkatan penyerapan tenaga kerja pertanian di Provinsi Jambi harus menjadi perhatian dan dukungan pemerintah daerah secara baik, bentuk dukungan tersebut dapat berupa kebijakan-kebijakan yang tepat dan dapat mendorong peningkatan Produk Domestik Regional Bruto, Pembangunan Daerah dan kesejahteraan masyarakat di Provinsi Jambi.
\end{abstract}

Kata kunci: PDRB, UMP, Tenaga kerja.

\section{PENDAHULUAN}

Kesempatan kerja merupakan salah satu indikator untuk menilai keberhasilan pembangunan ekonomi suatu negara, karena kesempatan kerja serta kuantitas dan kualitas tenaga kerja menjadi indikator fungsi yang menetukan keberhasilan pembangunan ekonomi suatu negara. Tenaga kerja merupakan sumber daya untuk menjalankan proses produksi serta distribusi barang dan jasa, sehingga tenaga kerja di sebut juga motor penggerak dalam pembangunan. Tenaga kerja juga sebagai sasaran mengembangkan pasar, penyerapan tenaga kerja itu sendiri diartikan cukup luas, menyerap tenaga kerja dalam maknanya menghimpun orang atau tenaga kerja di suatu lapangan usaha untuk dapat sesuai dengan usaha itu sendiri (Tambunan 2001). 
Penyerapan tenaga kerja merupakan suatu jumlah kuantitas tertentu dari tenaga kerja yang digunakan oleh suatu sektor atau unit usaha tertentu, daya serap tenaga kerja merupakan suatu model permintaan suatu unit usaha terhadap tenaga kerja dalam pasar kerja yang dipengaruhi oleh tingkat upah yang berlaku. penyerapan tenaga kerja juga didefinisikan sebagai jumlah tenaga kerja yang terserap pada suatu sektor dalam waktu tertentu, penyerapan tenaga kerja diturunkan dari fungsi produksi suatu aktivitas ekonomi. Produksi merupakan transformasi dari input atau masukan (faktor produksi) ke dalam output atau keluaran. Tambunan (2001) mengemukakan indikator penyerapan tenaga kerja adalah sebagai berikut: 1). Perubahan Upah Minimum, dimana Upah minimum yang berubah-ubah setiap tahunnya dapat mempengaruhi terhadap penyerapan tenaga kerja. Karena apabila tingkat upah naik maka perusahaan akan lebih memilih untuk tidak menambah jumlah tenaga kerja lalu menaikkan upah kepada pekerja yang sudah ada. 2). Banyak nya peluang atau penyerapan tenaga kerja diantara dapat dilihat dari pertumbuhan PDRB di suatu provinsi. Apabila tingkat PDRB meningkat maka semakin banyak juga tenaga kerja yang terserap. Karena kesejahteraan penduduk dapat dilihat dari seberapa besar pertumbuhan perekonomian di suatu daerah atau provinsi. 3). Laju Pertumbuhan Investasi, dimana investasi merupakan suatu faktor krusial bagi kelangsungan proses pembangunan ekonomi, atau pertumbuhan ekonomi jangka panjang.

Subekti (2007) mengemukakan permintaan tenaga kerja berkaitan dengan jumlah tenaga kerja yang dibutuhkan oleh suatu lapangan usaha, dimana faktor-faktor yang mempengaruhi penyerapan tenaga kerja adalah tingkat upah, nilai produksi dan investasi. Perubahan pada faktor-faktor tersebut akan mempengaruhi jumlah tenaga kerja yang diserap suatu lapangan usaha. Tingkat upah akan mempengaruhi tingkat biaya produksi dengan asumsi apabila tingkat upah meningkat maka akan terjadi hal-hal sebagai berikut: a). Naiknya tingkat upah akan meningkatkan biaya produksi yang selanjutnya meningkatkan harga per unit barang yang diproduksi, akibatnya banyak barang yang tidak terjual dan terpaksa produsen menurunkan jumlah produksinya. Sebaliknya turunnya target produksi akan mengakibatkan berkurangnya tenaga kerja yang dibutuhkan; b). Apabila upah naik (asumsi harga barang-barang modal lainnya tidak berubah) maka pengusaha ada yang lebih suka menggunakan teknologi padat modal untuk produksinya dan mengganti kebutuhan tenaga kerja dengan barang-barang modal seperti mesin dan lainnya.

Upah merupakan hal yang paling utama dalam ketenagakerjaan, karena tujuan orang bekerja adalah untuk mendapatkan upah yang akan digunakan untuk memenuhi kebutuhan hidupnya. Jika nilai upah yang ditawarkan oleh suatu perusahaan tersebut dinilai tidak 
mencukupi untuk memenuhi kebutuhan hidup pekerja, maka pekerja tersebut akan menolak pekerjaan yang ditawarkan. Untuk itu salah satu usaha yang dilakukan oleh pemerintah dalam mengatasi masalah ketenagakerjaan yaitu memperbaiki sistem upah melalui kebijakan upah minimum, penerapan kebijakan upah minimum merupakan usaha dalam rangka meningkatkan upah perkapita pekerja sehingga tingkat upah rata-rata tenaga kerja dapat meningkat.

Selain tingkat upah ada beberapa hal yang juga mendapat perhatian dari pemerintah sebagai upaya mengatasi permasalahan ketenagakerjaan yaitu produk domestik regional bruto dan investasi, Produk Domestik Regional Bruto (PDRB) merupakan nilai tambah atas barang dan jasa yang dihasilkan oleh berbagai unit produksi atau sektor di suatu daerah dalam jangka waktu tertentu. PDRB dapat mempengaruhi jumlah angkatan kerja yang bekerja dengan asumsi apabila nilai PDRB meningkat, maka jumlah nilai tambah output atau penjualan dalam seluruh unit ekonomi disuatu wilayah akan meningkat. Semakin besar output atau penjualan yang dilakukan perusahaan maka akan mendorong perusahaan untuk menambah permintaan tenaga kerja agar produksinya dapat ditingkatkan untuk mengejar peningkatan penjualan yang terjadi (Feriyanto, 2014).

Untuk mencapai tujuan penelitian terutama untuk mengenai kondisi penyerapan tenaga kerja sektor pertanian dilihat dari nilai sektor pertanian, upah minimum provinsi peneliti mengambil referensi dari penelitian terdahulu atas nama Dasri Lokiman dkk tahun 2013 dan Tarigan dan Sufhia (2018), dimana dalam penelitiannya Lokiman menjelaskan bahwa Upah Minimum Provinsi dan Investasi Swasta memiliki pengaruh secara bersama-sama terhadap Penyerapan Tenaga Kerja, secara parsial. Upah Minimum Provinsi juga memiliki pengaruh terhadap penyerapan Tenaga Kerja sedangkan Investasi Swasta tidak memiliki pengaruh terhadap penyerapan tenaga kerja. Selanjutnya Tarigan dan Sufhia (2018) mengemukakan bahwa investasi PMA dan PMDN dan PDRB berpengaruh positif dan signifikan terhadap penyerapan tenaga kerja pada sektor industry sedangkan UMP tidak memberikan pengaruh terhadap penyerapan tenaga kerja pada sektor industri.

Berdasarkan penjelasan yang dikemukakan pada latar belakang serta referensi penelitian terdahulu, maka peneliti ingin mengkaji Pengaruh PDRB Sektor Pertanian, Upah Minimum Provinsi Terhadap Penyerapan Tenaga Kerja Sektor Pertanian Di Provinsi Jambi.

\section{METODOLOGI}

Jenis data yang digunakan dalam penelitian ini adalah data sekunder, dimana data sekunder merupakan data yang bukan merupakan hasil olahan sendiri, seperti diunduh dari 
Badan Pusat Statistik; dokumen-dokumen pemerintah, atau organisasi tertentu; ataupun surat kabar; majalah; atau media cetak lainnya. Jenis data sekunder yang digunakan dalam penelitian ini adalah Data Tenaga Kerja Sektor Pertanian di Provinsi Jambi, Data nilai sektor pertanian atas dasar harga berlaku di Provinsi Jambi 2010-2019 serta Data Upah Minimum Provinsi Jambi periode tahun 2010-2019.

Metode analisis data yang digunakan didalam penelitian ini adalah analisis deskriptif dan analisis kuantitatif, dengan tujuan mendiskripsikan suatu permasalahan dengan menganalisis data dengan hal-hal yang berhubungan dengan angka-angka dan rumus perhitungan yang digunakan untuk menganalisis masalah yang sedang diteliti. Metode deskriptif digunakan untuk memberikan dan menjelaskan gambaran secara sistematis dan faktual mengenai perkembangan penyerapan tenaga kerja sektor pertanian, PDRB sektor pertanian, upah minimum provinsi, sedangkan metode kuantitatif digunakan untuk mengetahui faktor-faktor yang mempengaruhi penyerapan tenaga kerja sektor pertanian serta untuk melakukan pengujian terhadap hipotesis yang diajukan baik secara simultan maupun secara parsial.

Untuk menjawab permasalahan dan tujuan penelitian dipergunakan analisis deskriptif dengan mengunakan analisis perkembangan dengan persamaan $\mathrm{G}=\frac{P_{n}-P_{0}}{P_{0}} \times 100 \%$ Dimana G (merupakan Perkembangan Variabel), $P_{n}$ (Variabel tertentu pada tahun t) dan $P_{0}$ (Variabel tertentu pada tahun sebelumnya. Selanjutnya untuk mengetahui menjawab perumusan masalah kedua untuk melihat pengaruh faktor yang mempengaruhi variabel terikat maka digunakan model persamaan linear berganda dengan persamaan sebagai berikut:

$$
\mathrm{Y}=\beta_{0}+\beta_{1} X_{1}+\beta_{2} X_{2}+\text { et }
$$

Dimana

$$
\begin{array}{ll}
\mathrm{Y} & =\text { Penyerapan Tenaga Kerja Sektor Pertanian (Jiwa) } \\
X_{1} & =\text { Nilai Sektor Pertanian (Rupiah) } \\
X_{2} & =\text { Upah Minimum Provinsi (Rupiah) } \\
\beta_{0} & =\text { Intercept } \\
\beta_{1}, \beta_{2} & =\text { Koefisien Regresi } \\
\mathrm{e} & =\text { Nilai error penelitian }
\end{array}
$$

Pengujian Hipotesis dilakukan untuk melihat kekuatan dari suatu hasil perhitungan melalui pengujian statistik yakni uji $\left(\mathrm{R}^{2}\right.$ ), Uji Simultan (uji F), dan Uji Parsial (Uji t) untuk menguji tingkat sigfikansi koefisien regresi parsial (individual) dengan kriteria t statistik 


$$
\begin{aligned}
& \mathrm{H} 0=\alpha 1=\alpha 2=\alpha 3 \text { dan } \\
& \mathrm{H} 1=\alpha 1 \neq \alpha 2 \neq \alpha 3 \text { Nilai }
\end{aligned}
$$

Jika nilai $t$ hitung dibandingkan dengan nilai $t$ tabel Apabila $t$ hitung $>t$ tabel maka H0 diterima dan Ha di tolak, artinya terdapat pengaruh yang signifikasi antara variabel $\mathrm{X}$ terhadap variabel $\mathrm{Y}$. Apabila $\mathrm{t}$ hitung $<\mathrm{t}$ tabel maka $\mathrm{H} 0$ ditolak dan Ha diterima, artinya terdapat pengaruh yang tidak signifikan antara variabel $\mathrm{X}$ terhadap variabel $\mathrm{Y}$.

\section{HASIL}

Hasil penelitian memperlihatkan dimana data penyerapan tenaga kerja, PDRB sektor pertanian serta upah minimum Provinsi Jambi periode 2010-2019 tergambar pada Tabel 1 sebagai berikut:

Tabel 1

Data Penyerapan Tenaga Kerja, PDRB Sektor Pertanian Serta Upah Minimum Provinsi Jambi periode 2010-2019

\begin{tabular}{|c|c|c|c|c|c|c|}
\hline Tahun & $\begin{array}{c}\text { Tenaga } \\
\text { Kerja } \\
\text { (Jiwa) }\end{array}$ & $\begin{array}{c}\text { Perkemban } \\
\text { gan (\%) }\end{array}$ & $\begin{array}{c}\text { PDRB } \\
\text { Sektor } \\
\text { Pertanian } \\
\text { (Milyar } \\
\text { Rupiah) }\end{array}$ & $\begin{array}{c}\text { Perkembang } \\
\text { an } \\
(\%)\end{array}$ & $\begin{array}{c}\text { UMP } \\
\text { (Rupiah) }\end{array}$ & $\begin{array}{c}\text { Perkemba } \\
\text { ngan } \\
(\%)\end{array}$ \\
\hline 2010 & 42.369 & - & 23.627 & - & 900.000 & - \\
\hline 2011 & 36.507 & $-13,83$ & 27.121 & 14,78 & 1.028 .000 & 14,22 \\
\hline 2012 & 42.523 & 16,47 & 27.833 & 12,64 & 1.142 .500 & 11,13 \\
\hline 2013 & 36.843 & $-13,35$ & 33.312 & 19,68 & 1.300 .000 & 13,78 \\
\hline 2014 & 30.084 & $-18,34$ & 37.967 & 13,97 & 1.502 .023 & 15,54 \\
\hline 2015 & 31.668 & 5,26 & 43.793 & 15,34 & 1.710 .000 & 13,84 \\
\hline 2016 & 33.231 & 4,93 & 51.441 & 17,46 & 1.906 .650 & 11,5 \\
\hline 2017 & 35.271 & 6,13 & 56.325 & 9,49 & 2.063 .948 & 8,25 \\
\hline 2018 & 38.373 & 8,79 & 57.800 & 2,61 & 2.243 .718 & 8,02 \\
\hline 2019 & 41.231 & 7,44 & 59.964 & 3,74 & 2.400 .000 & 6,96 \\
\hline Rata-rata & 36.810 & 0,35 & 41.918 & 12,190 & 1.619 .684 & 11,471 \\
\hline
\end{tabular}

Sumber: BPS, Jambi Dalam Angka. 2020 (Data Diolah)

Hasil penelitian tersebut memperlihatkan dimana dari tahun 2010 sampai tahun 2019, penyerapan tenaga kerja di sektor pertanian Provinsi Jambi tertinggi terjadi pada periode tahun 2012 mencapai 16,47\% dari tahun sebelumnya 2011 yang pertumbuhannya mengalami penurunan mencapai $-13,83 \%$. 


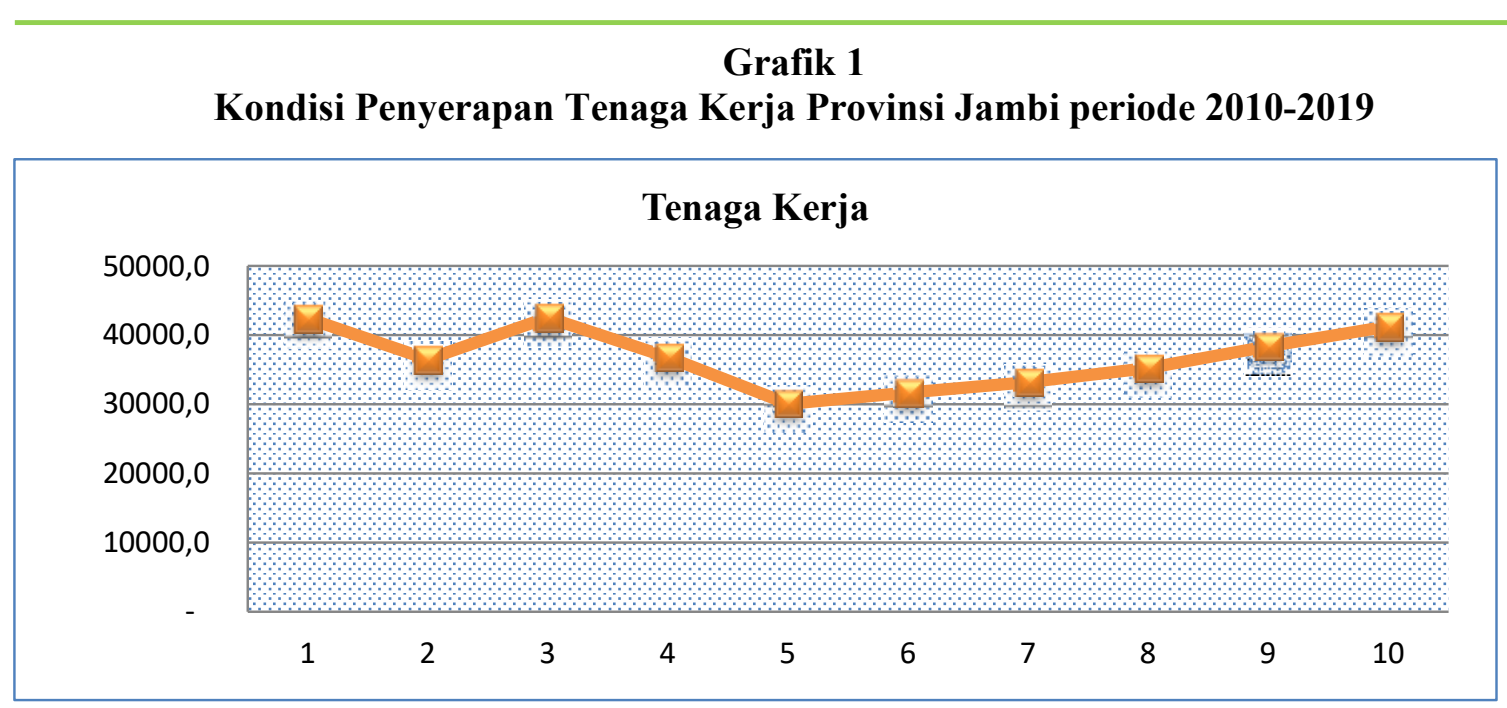

Sumber: BPS, Jambi Dalam Angka. 2020 (Data Diolah)

Pada Grafik 1 Juga terlihat dimana kondisi penyerapan tenaga kerja di Provinsi Jambi yang terjadi pada tahun 2014 sebesar -18,34\% akibat sektor pertanian di Provinsi Jambi yang mulai tergeserkan dengan sektor lainnya yang ada di Provinsi ini. secara rata-rata perkembangan tenaga kerja sektor pertanian yang terjadi di Provinsi Jambi adalah sebesar $0,35 \%$,

\section{Grafik 2}

Kondisi PDRB Sektor Pertanian Provinsi Jambi periode 2010-2019

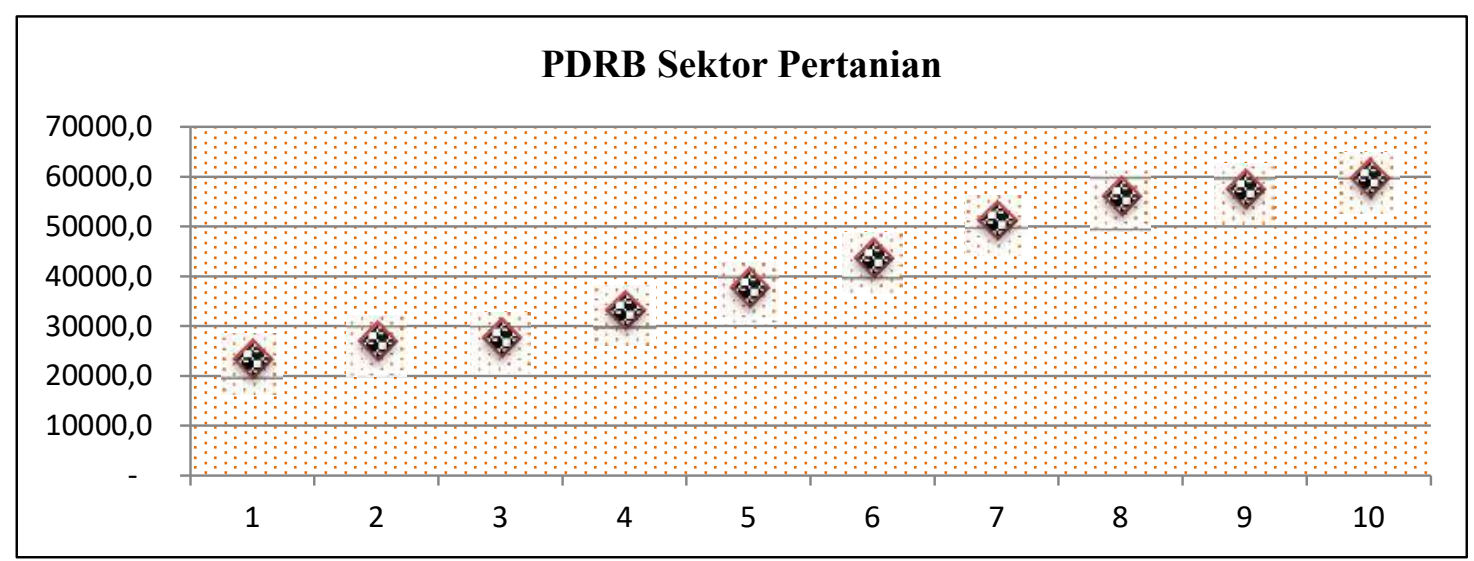

Sumber: BPS, Jambi Dalam Angka. 2020 (Data Diolah)

Grafik 2 memperlihatkan bahwa PDRB sektor pertanian diProvinsi Jambi dari tahun 2010 sampai dengan tahun 2019 menunjukan kondisi yang berfluktuatif dengan kenaikan tertinggi pada tahun 2013 sebesar 19,68\% dan terendah pada tahun 2018 sebesar 2,61\%. Secara rata-rata PDRB sektor pertanian provinsi Jambi dalam periode penelitian tersebut adalah sebesar $11,19 \%$ pertahun. 


\section{Grafik.3}

Perkembangan Upah Minimum Provinsi Jambi periode 2010-2019

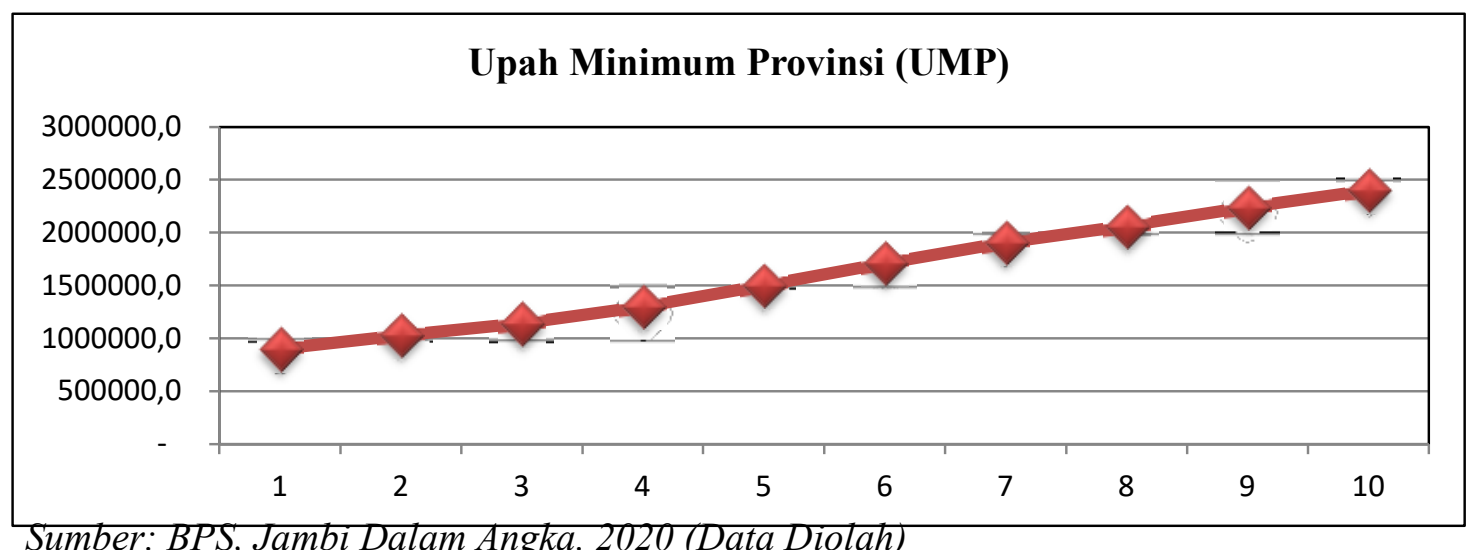

Sumber: BPS, Jambi Dalam Angka. 2020 (Data Diolah)

Kondisi Upah Minimum Provinsi di Provinsi Jambi yang tergambar pada Grafik 3. terlihat bahwa pada periode tahun 2010 sampai dengan tahun 2019 mengalami perkembangan dengan trent positif. Perkembangan tertinggi UMP Provinsi Jambi yaitu pada tahun 2014 sebesar 15,54\%, sedangkan terendah terjadi pada tahun 2019 sebesar 6,96\%. secara rata-rata Perkembangan UMP Provinsi Jambi pada periode penelitian yaitu sebesar 11,471\% pertahun. Hasil analis regresi untuk mengetahui apakah PDRB sektor pertanian dan UMP mempengaruhi penyerapan tenaga kerja sektor pertanian di Provinsi Jambi, didapatkan hasil sebagai berikut:

Tabel 2

Hasil Analisis Regresi pengaruh PDRB sektor pertanian dan UMP terhadap penyerapan tenaga kerja sektor pertanian di Provinsi Jambi

Model Summary

\begin{tabular}{|c|c|c|c|c|c|c|c|c|}
\hline Model & $\mathrm{R}$ & \multicolumn{2}{|c|}{ R Square } & \multicolumn{2}{|c|}{ Adjusted R Square } & \multicolumn{3}{|c|}{ Std. Error of the Estimate } \\
\hline 1 & $.911^{\mathrm{a}}$ & \multicolumn{2}{|c|}{.831} & \multicolumn{2}{|r|}{.788} & \multicolumn{3}{|r|}{.20429} \\
\hline \multicolumn{9}{|c|}{ ANOVA $^{a}$} \\
\hline \multicolumn{2}{|l|}{ Model } & \multicolumn{3}{|c|}{ Sum of Squares } & $\mathrm{df}$ & Mean Square & $\mathrm{F}$ & Sig. \\
\hline \multirow[t]{3}{*}{1} & Regression & \multicolumn{3}{|r|}{1.638} & 2 & .819 & 19.624 & $.001^{\mathrm{b}}$ \\
\hline & Residual & \multicolumn{3}{|r|}{.334} & 8 & .042 & & \\
\hline & Total & \multicolumn{3}{|r|}{1.972} & 10 & & & \\
\hline \multicolumn{9}{|c|}{ Coefficients $^{\mathbf{a}}$} \\
\hline \multicolumn{6}{|c|}{ Unstandardized Coefficients } & $\begin{array}{c}\text { Standardized } \\
\text { Coefficients }\end{array}$ & & \\
\hline \multicolumn{3}{|l|}{ Model } & & $\mathrm{B}$ & Std. Error & Beta & $\mathrm{t}$ & Sig. \\
\hline \multirow[t]{3}{*}{1} & \multicolumn{2}{|l|}{ (Constant) } & & -26.537 & 9.499 & & -2.794 & .023 \\
\hline & \multirow{2}{*}{\multicolumn{2}{|c|}{\begin{tabular}{|l} 
Nilai Sektor Pertanian \\
UMP
\end{tabular}}} & & .628 & .413 & .359 & 2.520 & .001 \\
\hline & & & & 6.770 & 2.654 & .602 & 2.551 & .000 \\
\hline
\end{tabular}

Sumber: BPS, Jambi Dalam Angka. 2020 (Data Diolah) 
Hasil analisis regresi liner berganda seperti pada Tabel 2. diatas lebih rinci dapat disampaikan sebagai berikut

Konstanta (a) : -26.539 nilai konstanta bernilai negatif artinya jika PDRB sektor pertanian dan UMP dianggap tidak berubah atau penambahan sama dengan 0 maka mempengaruhi penyerapan tenaga kerja sektor pertanian lebih kecil sebesar 26.539 .

Koefisien $X_{1}$ : 0.628 , koefisien variabel nilai PDRB sektor pertanian bernilai positif artinya apabila PDRB sektor pertanian meningkat 1\% maka penyerapan tenaga kerja pertanian meningkat 0,628 persen dengan asumsi variabel independent nilai lainnya konstan.

Koefisien $X_{2}$ : 6.770, koefisien variabel Upah Minimum Provinsi bernilai positif, artinya apabila Upah Minimum Provinsi naik, maka penyerapan tenaga kerja sektor pertanian akan mengalami kenaikan nilai sebesar 6.77 persen dengan asumsi variabel independent lain nilainya konstan.

$\mathrm{R}^{2}(0.831) \quad$ : Menunjukan bahwa 83.1 persen penyerapan tenaga kerja sektor pertanian dipengaruhi oleh PDRB sektor pertaian dan UMP sedangkan 16.9 persen dijelaskan oleh faktor-faktor lain yang tidak dibahas dalam model ini.

Uji F : Pada tingkat keyakinan 0.05 persen diperoleh nilai $\mathrm{f}$ tabel 4.46 nilai f hitung sebesar $19.624(19.624>4.46)$ sehingga Ho ditolak artinya PDRB sektor pertanian dan UMP secara bersama-sama berpengaruh signifikan terhadap penyerapan tenaga kerja sektor pertanian.

Uji t : t-hitung PDRB sektor pertanian sebesar 2.520 lebih besar dari nilai t tabel $(2.520<1.859)$ dinyatakan Ho ditolak dan Ha diterima, artinya PDRB sektor pertanian secara parsial berpengaruh positif dan signifikan terhadap penyerapan tenaga kerja sektor pertanian. Nilai t hitung UMP sebesar 2.551 dan t tabel 1.859 atau $(2.551>1.859)$ juga menjelaskan dimana Ho ditolak dan Ha diterima, artinya UMP secara parsial mempengaruhi penyerapan tenaga kerja sektor pertanian di provinsi Jambi. 


\section{PEMBAHASAN}

Hasil penelitian yang memperlihatkan penyerapan tenaga kerja sektor pertanian akan bernilai negatif jika PDRB sektor pertanian dan UMP di Provinsi Jambi tidak mengalami peningkatan, selanjutnya jika nilai PDRB sektor pertanian dan UMP meningkat 1\% maka penyerapan tenaga kerja pertanian juga meningkat. Kondisi tersebut menggambarkan pentingnya kontribusi PDRB dan UMP terhadap peningkatan penyerapan tenaga kerja pertanian di Provinsi Jambi.

Persoalan ketenagakerjaan di Provinsi Jambi merupakan persoalan daerah yang harus dicari solusi penyelesaiannya secara baik dan bijaksana, karena persoalan ketenagakerjaan tidak semata-mata persoalan demografis tetapi juga memiliki dimensi ekonomi yang kuat terhadap pembangunan daerah dan kesejahteraan masyarakat. Kondisi pertumbuhan penduduk yang tidak seimbang dengan ketersediaan lapangan pekerjaan yang ada di daerah telah memunculkan fenomen social yang baru yaitu semakin meningkatnya angka penganguran dan kemiskinan.

Pemerintah Pusat dan Pemerintah Daerah juga memiliki peran sangatlah penting selain sebagai kontrol pembangunan nasional dan daerah peranya juga diharapkan agar roda perekonomian berjalan baik sesuai dengan harapan masyarakat. Beberapa kebijakan Pemerintah Pusat untuk mendorong tumbuhnya perekonomian di daerah salah satunya yaitu tertuang dalam Undang-undang No. 23 Tahun 2014 (UU Otonomi Daerah), dimana pemerintah Pusat telah memberikan kebebasan sepenuhnya bagi pemerintah daerah untuk mengurus rumah tangganya sendiri secara baik dan bijaksana. Kebijakan tersebut juga sangat berkaitan bagaimana mendorong investasi dapat tumbuh di daerah semakin baik, karena investasi merupakan faktor yang sangat mempengaruhi secara positif terhadap pertumbuhan ekonomi di suatu wilayah.

Beberapa kebijakan pemerintah pemerintah daerah Provinsi Jambi dalam rangka meningkatakan Produk Domestik Regional Bruto (PDRB) khususnya di sector pertanian yaitu memberikan berbagai bentuk kemudahan-kemudahan bagi investor untuk menanamkan modal di wilayah. Adapun bentuk kebijakan tersebut yaitu: 1) Kebijakan pembebasan pajak (tax holiday), yaitu kebijakan yang mengurangi atau bahakan menghapuskan pajak saat investor memulai penanaman modal, pajak baru akan diambil apabila usaha yang dilakukan investor tersebut telah memperoleh hasil; 2) Memberikan kepastian hukum, juga merupakan salah satu upaya pemerintah guna meningkatkan minat investor untuk berinvestasi. 3). Melaksnakan 
upaya promosi untuk memberikan informasi kepada pihak investor tentang sumber daya yang potensial yang dimiliki Provinsi Jambi. Sehingga dengan kebijakan tersebut diharapkan juga iklim investasi di provinsi Jambi dapat meningkat, dan akan berdampak terbukanya lapangan pekerjaan baru dan tentu akan meningkatkan pendapatan perkapita dan pertumbuhan ekonomi di Provinsi Jambi.

\section{KESIMPULAN}

Hasil penelitian yang ditemukan dapat ditarik kesimpulan sebagai berikut:

1. PDRB sektor pertanian Provinsi Jambi selama periode penelitian berfluktuasi, pertumbuhan nilai PDRB sektor pertanian dan upah minimum Provinsi Jambi terhadap penyerapan tenaga kerja sektor pertanian Provinsi Jambi pada periode peneltian. Hasil penelitian menunjukan terdapat hubungan yang sangat signifikan antara pertumbuhan nilai PDRB sektor pertanian dan upah minimum Provinsi Jambi terhadap penyerapan tenaga kerja sektor pertanian Provinsi Jambi pada periode peneltian.

2. Penyerapan tenaga kerja sektor pertanian di Provinsi Jambi mempunyai nilai yang turun naik, nilai tersebut menjadi acuan bahwa ada keengganan masyarakat di Provinsi Jambi untuk bekerja dalam bidang pertanian, penulis menyarankan agar pemerintah dalam hal ini Dinas Pertanian dan Dinas Perindustrian Dan Tenaga Kerja turun kemasyarakat untuk memberikan semacam penyuluhan ataupun motivasi untuk kembali meyakinkan kemasyarakat bahwa sektor pertanian dapat memberikan mereka pendapatan yang layak dan juga menjanjikan bagi kehidupan masyarakat sehari-hari.

\section{DAFTAR PUSTAKA}

Aisah, H.N.P., \& Didit P. (2018) Analisis Pengaruh Upah Minimum Regional, Produk Domestik Regional Bruto, Dan Pendidikan Terhadap Penyerapan Tenaga Kerja Industri Manufaktur Di Kabupaten/ Kota Wilayah Provinsi Jawa Tengah. Skripsi thesis, Universitas Muhammadiyah Surakarta.

Arsyad, L. (2003). Ekonomi Pembangunan, UPP YKPN, Yogyakarta

Badan Pusat Statistik. (2020). Indikator Ekonomi. Jakarta.

Dari, L., Debby, R., \& Antonius L. (2015) Pengaruh Upah Minimum Provinsi (UMP dan Investasi Swasta Terhadap Penyerapan Tenaga Kerja Dan Dampaknya Pada PDRB di Kota Manado Tahun 2003-2012. Jurnal Berkala Ilmiah Efisiensi, 15 (1). 
Feriyanto, N. (2014). Ekonomi Sumber Daya Manusia Dalam Perspektif Indonesia. Yogyakarta: UPP STIM YKPN.

Jhingan, M. L. (2004). Ekonomi Pembangunan dan Perencanaan. PT. Raja Grafindo Persada, Jakarta.

Prathama. (2016). Teori Ekonomi Makro: Suatu Pengantar. Lembaga Penerbit Fakultas Ekonomi Universitas Indonesia, Jakrta.

Soemitro, D. (20040. Perkembangan Pemikiran Ekonomi Dasar Teori Ekonomi Pertumbuhan dan Ekonomi Pembangunan. LP3ES, Jakarta.

Soleh, A. (2017). Masalah ketenagakerjaan dan pengangguran di Indonesia. Jurnal Ilmiah Cano Ekonomos, 6(2), 83-92.

Subekti, N.A., Syafruddin, R. Efendi, dan S. Sunarti. 2007. Morfologi tanaman dan fase pertumbuhan jagung. Balai Penelitian Tanaman Serealia. Maros

Sukirno, S. (2004). Ekonomi Pembangunan. Penerbit Ghalia Indonesia, Jakarta.

Tambunan. (2001). Perekonomian Indonesia Teori dan Temuan Empiris. Ghalia Indonesia, Jakarta.

Tarigan, S. (2018). Pengaruh Investasi, PDRB, Upah Minimum Provinsi Terhadap Penyerapan Tenaga Kerja Pada Sektor Industri di Sumatera Utara. Fakultas Ekonomi dan Bisnis, Universitas Sumatera Utara, Medan.

Trisno. (2008). Ekonomi Pembangunan Surakarta: UNS Press 